\title{
Newly Developed Nonlinear Vehicle Model for an Active Anti- roll Bar System
}

\author{
Noraishikin Zulkarnain ${ }^{1}$, Hairi Zamzuri ${ }^{2}$, Sarah 'Atifah Saruchi ${ }^{3}$, Mohd Marzuki Mustafa ${ }^{4}$, Siti \\ Salasiah Mokri ${ }^{5}$, Nurbaiti Wahid ${ }^{6}$, Siti Nor Zawani Ahmmad ${ }^{7}$, Alias Jedi ${ }^{8}$ \\ ${ }^{\mathbf{1 , 4}, \mathbf{5}}$ Centre for Integrated Systems Engineering and Advanced Technologies (INTEGRA), \\ Faculty of Engineering and Built Environment, Universiti Kebangsaan Malaysia, 43600 Bangi, Selangor, Malaysia \\ ${ }^{1,8}$ Centre of Research in Engineering Education and Built Environment (PEKA) \\ ${ }^{8}$ Centre of Integrated Design for Advanced Mechanical Design (PRISMA, Faculty of Engineering and Built \\ Environment, Universiti Kebangsaan Malaysia, 43600 Bangi, Selangor, Malaysia \\ ${ }^{2,3}$ Vehicle System Engineering, Malaysia-Japan International Institute of Technology, Universiti Teknologi \\ Malaysia, 54100 Kuala Lumpur, Malaysia \\ ${ }^{6}$ Faculty of Electrical Engineering, Universiti Teknologi MARA, Universiti Teknologi MARA, 23000 Dungun, \\ Terengganu, Malaysia \\ ${ }^{7}$ Instrumentation \& Control Engineering, Universiti Kuala Lumpur, Malaysian Institute of Industrial Technology, 81750 \\ Masai, Johor, Malaysia
}

\begin{tabular}{|c|c|}
\hline Article Info & ABSTRACT \\
\hline Article history: & This paper presents the development of a newly developed nonlinear vehicle \\
\hline Received March 30, 2018 & $\begin{array}{l}\text { model is used in the validation process of the vehicle model. The parameters } \\
\text { chosen in a newly developed vehicle model is developed based on CARSIM }\end{array}$ \\
\hline Revised Jul 24, 2018 & vehicle model by using non-dominated sorting genetic algorithm version II \\
\hline Accepted Nov 11, 2018 & $\begin{array}{l}\text { (NSGA-II) optimization method. The ride comfort and handling } \\
\text { performances have been one of the main objective to fulfil the expectation of }\end{array}$ \\
\hline Keywords: & $\begin{array}{l}\text { customers in the vehicle development. Full nonlinear vehicle model which } \\
\text { consists of ride, handling and Magic tyre subsystems has been derived and }\end{array}$ \\
\hline Anti-roll bar & developed in MATLAB/Simulink. Then, optimum values of the full \\
\hline NSGA-II & $\begin{array}{l}\text { onitive functions are established based on RMS error between simulation } \\
\text { objective funs }\end{array}$ \\
\hline Optimization & and benchmark system. A stiffer suspension provides good stability and \\
\hline Ride and handling & handling during manoeuvres while softer suspension gives better ride quality. \\
\hline Vehicle model & $\begin{array}{l}\text { The final results indicated that the newly developed nonlinear vehicle model } \\
\text { is behaving accurately with input ride and manoeuvre. The outputs trend are } \\
\text { successfully replicated. }\end{array}$ \\
\hline
\end{tabular}

Copyright $@ 2018$ Institute of Advanced Engineering and Science. All rights reserved.

\section{Corresponding Author:}

Noraishikin Zulkarnain,

Centre for Integrated Systems Engineering and Advanced Technologies (INTEGRA),

Faculty of Engineering and Built Environment,

Universiti Kebangsaan Malaysia, 43600 Bangi, Selangor, Malaysia

Email: shikinzulkarnain@ukm.edu.my

\section{INTRODUCTION}

Vehicle suspension system is used to keep apart the vehicle from uncomfortable vibrations transmitted from the road excitation on the tyres and the driver. During a manoeuvre, it can keep the vehicle under control as it transmits the control forces back to the tyres [1]-[4]. The ride comfort and handling performances have been the major development objectives of vehicles in order to fulfil the expectation of customers in the development of mechanical and electronics vehicle technology. Thus, designing a suitable suspension system is always an important research issue for attaining the desired vehicle quality. Currently, 
there are so many researchers in active suspension system field around the world that tackle these issues. However, some of them prefer to use active suspension others prefer to focus on the anti-roll bar itself.

Currently, an automotive engineer encounters many challenges in trying to have a good ride and handling whilst at the same time in cornering or straight line. Thus, this research proposed to investigate a new control design to provide the required active roll control of the anti-roll bar system for a ground vehicle. At the same time, to be able to find an improvement in handling capabilities without sacrificing the ride comfort.

Due to the growing market share of light duty vehicle, automotive engineers have been prompted to examine body roll minimization strategies. During driving manoeuvres in high centre of gravity vehicles due to its roll-over, dangerous operating scenarios may induce drivers to drive in an aggressive way such as high lateral acceleration, rapid tire dilation and emergence lane change in [5]. Commercially, to counteract the roll movement, the most used topology is by using anti-roll bar. This bar can be implemented in a passive as well in active topology, where some of the most important parameters are again performance, energy consumption and costs [6].

From the previous researches, most researchers used genetic algorithm to optimise the system parameter such as routing in networks, job shop scheduling problem and isothermal liquid phase kinetic sequence [7]-[9]. Moreover, the Non-Dominated Sorting Genetic Algorithm II (NSGA-II) is proving to be a robust optimization algorithm for a wide range of multi-objective problems. The NSGA II Pareto ranking algorithm is an elitist system and maintains an external archive of the Pareto solutions [10].

Trade-off analysis is the one of the principles of active anti-roll bar system. It can help decision makers achieve the ride and handling performance requirements at the same time. However, the trade-off analysis in an active ant-roll bar system for tilt control design using NSGA-II are yet available in the literature [11]. Therefore, in this paper, a general methodology is proposed for conducting trade-off analysis for the selection problem of multi-objective of ride and handling for ground vehicle. A general trade-off based on multi-objective optimization framework for an active anti-roll bar system by optimising the novel control strategy parameters are established in this research [12]-[13].

Therefore, in this paper the newly developed nonlinear vehicle model for an active anti-roll bar system has been used NSGA-II optimization method for the future used of the controller design. This paper is organized as follows. In the next section, the full nonlinear vehicle model and vehicle parameters are presented. Then, the following section describes the newly developed nonlinear vehicle model. The fourth section shows the verification of newly developed vehicle model with CARSIM Model. Finally, the conclusion and future works are being concluded and suggested in the last section.

\section{FULL NONLINEAR VEHICLE MODEL}

A full nonlinear vehicle model described by using mathematical equations was developed as a MATLAB/Simulink model and was validated by comparing results from the double lane change test with speed $70 \mathrm{~km} / \mathrm{h}$. The steering input was used as the input to the simulation steering wheel angle and divided by a gain to represent the steer angle to the wheel in the vehicle model. The ride test was performed with CARSIM's input which are roll bump signal, pitch bump signal and combination pitch and roll bump signal with $20 \mathrm{~km} / \mathrm{h}$. The whole vehicle model consists of five main sub-models i.e. ride model, tyre model, handling model, side slip angle model and longitudinal slip ratio model as illustrated in Figure 1.

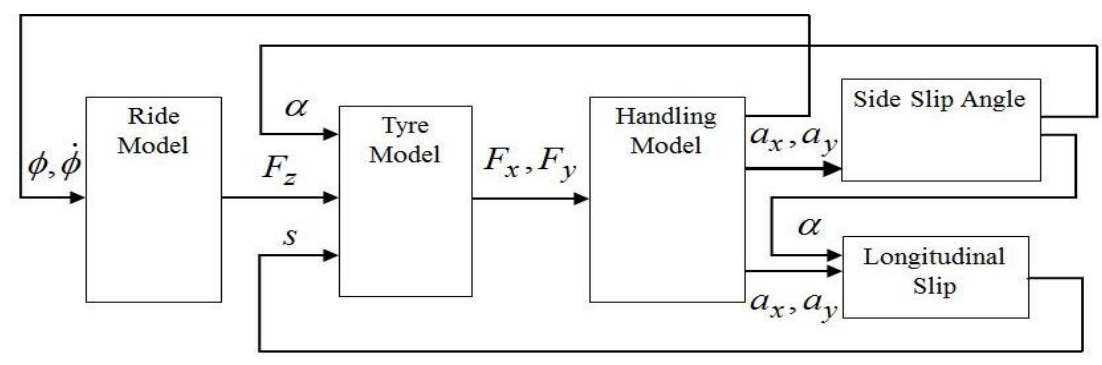

Figure 1. Full vehicle model

\section{NEWLY DEVELOPED NONLINEAR VEHICLE MODEL}

A new methodology is proposed to optimise the parameters of full nonlinear vehicle model based on ride and handling performances. The objective is to find the optimum values of the full nonlinear vehicle 
parameters. The block diagram configuration of methodology on development of nonlinear vehicle model is illustrated in Figure 2.

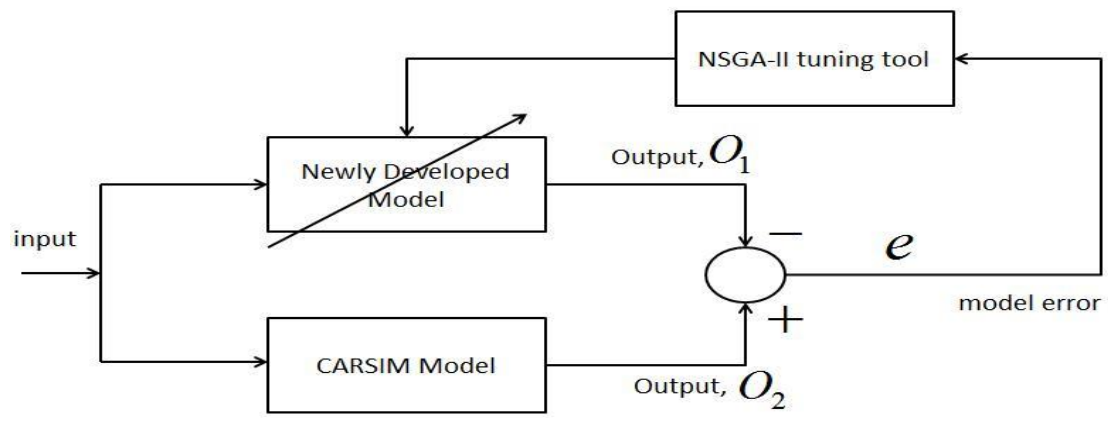

Figure 2. Newly developed vehicle model block diagram configuration

The two objective functions are established based on RMS error between simulation and benchmark system. This is done by optimizing the nonlinear vehicle parameters by comparing with output response based on commercial available vehicle dynamic software (CARSIM). The vehicle dynamic software is used as a benchmark in order to provide similar results in vehicle model. Newly developed nonlinear vehicle model must fulfil some conflicting area. Among those is ride comfort which is attained by minimizing the error of body roll angle in speed bump test. While, a good handling of a vehicle is a desirable property which is achieved by minimizing the error of body roll angle in steering test.

Objective 1 in the following form, which is consisted of RMS error value of the vehicle body roll angle for the handling performance means when the test input is handled in steering part as described in Equation 1. A small value of $f_{1}$ indicate good ride performance. Objective function 2 is built also using the mathematical formula of RMS error. RMS error value of the vehicle body roll angle for the ride performance means when the test input is handled in speed bump test as declared in Equation 3. A small value of $f_{2}$ indicate good ride performance.

The objective functions considered are minimization of (i) R.M.S error value of the vehicle body roll angle, which is for the handling performance on steering input test and (ii) R.M.S error value of the vehicle body roll angle, which is for the ride quality on the Speed Bump test. The following relations express these two objectives:

(i.) $O b j 1, f_{1}=$ R.M.S error value of the vehicle body roll angle, which is for the handling performance on steering input test (Double Lane Change)

$$
\begin{aligned}
& e_{r m s 1}=\sqrt{\frac{1}{T} \int_{0}^{T} O_{1}^{2}(t) d t}-\sqrt{\frac{1}{T} \int_{0}^{T} O_{2}^{2}(t) d t} \\
& f_{1}=\left|e_{r m s 1}\right|
\end{aligned}
$$

where $T$ is the transition time and the constraint function,

$$
w_{1}=\left\{\begin{array}{l}
f_{1}, f_{1} \geq 0 \\
0, \text { Otherwise }
\end{array}\right.
$$

(ii.) $O b j 2, f_{2}=$ R.M.S error value of the vehicle body roll angle, which is for the ride quality on the Speed Bump test

$$
\begin{aligned}
& e_{r m s 2}=\sqrt{\frac{1}{T} \int_{0}^{T} O_{1}^{2}(t) d t}-\sqrt{\frac{1}{T} \int_{0}^{T} O_{2}^{2}(t) d t} \\
& f_{2}=\left|e_{r m s 2}\right|
\end{aligned}
$$

where the constraint function is given by: 


$$
w_{2}= \begin{cases}f_{2}, & f_{1} \geq 0 \\ 0, & \text { Otherwise }\end{cases}
$$

Therefore, the objective function with constraint is given by:

$$
F(x)=f_{x}+R_{x} w_{x}
$$

Where $R_{x}$ is the penalty parameter which is for $R_{1}$ equal to 0.5 and $R_{2}$ also is 0.5 respectively. The value of penalty function is equal for both objectives in order to get equal trade-off between both objectives. In order to get the optimal solutions of parameter design for a newly developed nonlinear vehicle model, the RMS error of roll angle value is chosen as an objective function. From literature, the main goal of using anti-roll bar is to reduce the body roll [14]-[15]. For that reason, only the roll angle output is considered in optimization process.

The newly developed nonlinear vehicle model be able to fine-tuned by choosing the suitable value of parameters are listed in Table 1 . The eleven parameters chosen to optimise are roll axis moment inertia, $I_{r}$, spring stiffness at the front right, $K_{s f r}$, spring stiffness at the front left, $K_{s f l}$, spring stiffness at the rear right, $K_{s r r}$, spring stiffness at the rear left, $K_{s r l}$, damping stiffness at the front right, $C_{s f r}$, damping stiffness at the front left, $C_{s f l}$, damping stiffness at the rear right, $C_{s r r}$, damping stiffness at the rear left, $C_{s r l}$, roll spring stiffness, $K_{\phi}$ and roll damping stiffness, $C_{\phi}$. Table 1 shows the design variables, their bounds for newly developed nonlinear vehicle model and also initial design referring from work done by Hudha et. al. [16]. In this study, the value of $I_{r}, K_{s f r}, K_{s f l}, K_{s r r}, K_{s r l}, C_{s f r}, C_{s f l}, C_{s r r}, C_{s r l}, C_{\phi}$. and $K_{\phi}$. are observed as eleven design variables to be optimally found based on multi-objective optimization of two different objective functions [17]. The optimization problem is solved using Elitist Non-Dominated Sorting Genetic Algorithm (NSGA-II) [18]-[19]. Since it is a multi-objective optimization, a number of optimal solutions have been obtained and it is shown in the Figure 3 in which every solution is non-dominated by other solutions.

Table 1. Design Variables and Lower-upper Bounds for Newly Developed Model

\begin{tabular}{ccc}
\hline Design Variable & lower-upper & Initial Design \\
\hline$I_{r}$ & $100-1000$ & 700 \\
$K_{s f r}, K_{s f l}, K_{s r r}, K_{s r l}$ & $500-1000$ & 750 \\
$C_{s f r}, C_{s f l}, C_{s r r}, C_{s r l}$ & $20000-40000$ & 30000 \\
$C_{\phi}$ & $100-4000$ & 3495.7 \\
$K_{\phi}$ & $100-60000$ & 56957 \\
\hline
\end{tabular}

These objective functions are considered in a Pareto optimization process to obtain some important trade-offs among the conflicting objectives, simultaneously. The evolutionary process of multi-objective optimization is accomplished with a population size of 30 which has been chosen with probability of crossover and probability of mutation as 0.8 and 0.1 , respectively. These parameters setting of NSGA-II optimization method are shown in Table 2. A total number of 30 non-dominated optimum design points have been obtained. In order to analyse Pareto set and select good solutions, it is widely accepted that visualization tools are valuable to provide the decision maker in meaningful way. It is normally easy to make an accurate graphical analysis of the Pareto set points for a two-dimensional problem but for higher dimensions it becomes more difficult [20]-[22]. According to Pareto chart in Figure 3, a solution in central region of the trade-off is chosen for analysis. Therefore, the choice of parameters optimization for nonlinear model are based on the trade-off between both situations and gives the result in the Table 3 .

Table 2. NSGA-II User Defined Parameters

\begin{tabular}{cc}
\hline Parameter setting & Value \\
\hline Number of generation & 500 \\
Population Size & 30 \\
Probability of Crossover & 0.8 \\
Probability of Mutation & 0.1 \\
Distribution index in SBX & 20 \\
Distribution index in polynomial mutation & 20 \\
\hline
\end{tabular}

BEEI, Vol. 7, No. 4, December 2018: $529-537$ 
Table 3. The Best Parameter Optimization of Newly Developed Nonlinear Model by NSGA-II

\begin{tabular}{cc}
\hline Parameter & Value \\
\hline$I_{r}$ & 825 \\
$K_{s f l}$ & 798 \\
$K_{s r l}$ & 802 \\
$C_{s f l}$ & 34560 \\
$C_{s r l}$ & 36008 \\
$K_{\phi}$ & 57240 \\
$K_{s f r}$ & 829 \\
$K_{s r r}$ & 813 \\
$C_{s f r}$ & 35019 \\
$C_{s r r}$ & 35009 \\
$C_{\phi}$ & 3905 \\
\hline
\end{tabular}

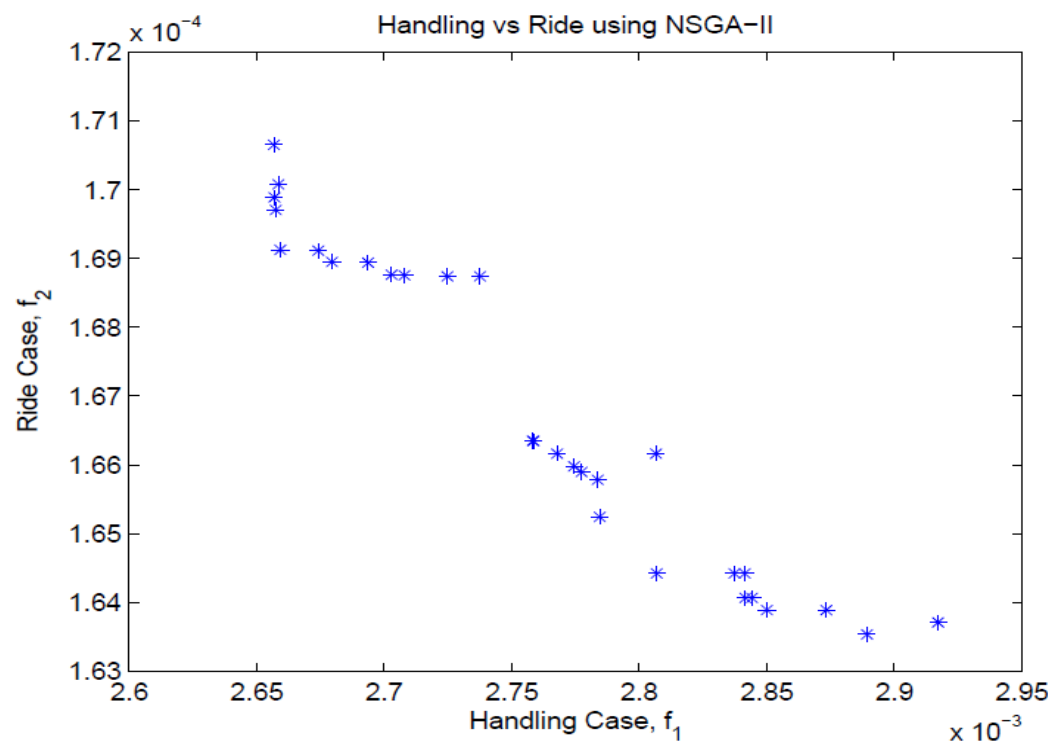

Figure 3. RMS error roll angle in handling vs RMS error roll angle in ride: optimal front

\subsection{Verification of Newly Developed Vehicle Model with CARSIM Model}

The newly developed nonlinear vehicle model using NSGA-II optimization method is verified with CARSIMEd version 4.51, a well-known vehicle dynamics software in order to determine its output response effectiveness. The dynamics behaviour of a vehicle obtained from CARSIMEd.

Is used as a benchmark for the 14 DOF nonlinear vehicle model under the same input conditions. Therefore, a performance comparison with benchmark vehicle is required. As a benchmark for validation purpose, a vehicle dynamic analysis software, CARSIM is used. The comparison between the full vehicle model with CARSIM benchmark is done by comparing the vehicle output response trend.

This study is focused on both ride and handling parts of vehicle dynamic. Thus, the selected appropriate vehicle handling output responses are selected including roll angle and roll rate for validation is preferable. While, the chosen suitable vehicle ride output components also used roll angle and roll rate taken in consideration respectively. In the validation process, a comparison of the performance output trend of newly nonlinear vehicle model with CARSIM benchmark vehicle requires proper handling and ride test procedure. As such, two types of analysis procedures are used for the validation purpose which are roll mode bump and double lane change manoeuvre.

\subsubsection{Ride Analysis Result}

As for the ride test analysis, a rolling mode test is used [23]. For this, only one side of the vehicle hits the bump i.e. front left side and rear left side, to create rolling effect in the rolling mode test. The bumps were arranged in a way that it created the rolling effect. The dimension of the bumps used in this simulation is height at $0.075 \mathrm{~m}$, weight at $0.11 \mathrm{~m}$ and length of $2.44 \mathrm{~m}$. The vehicle was driven at a constant speed of 20 $\mathrm{km} / \mathrm{h}$. Figure 4 shows the illustrations of the test bumps. In the roll mode test, only the left side of the vehicle will hop on and hop down from the bump in order to model this condition, the front left road input $Z_{r f l}$ and the rear left road input $Z_{r r l}$ be given that the road input for the right hand side will be considered as zero.

Newly Developed Nonlinear Vehicle Model for an Active Anti-roll Bar System (Noraishikin Zulkarnain) 
Figure 5 shows the simulation and the benchmark results for this mode indicating good correlation in terms of similar trends.

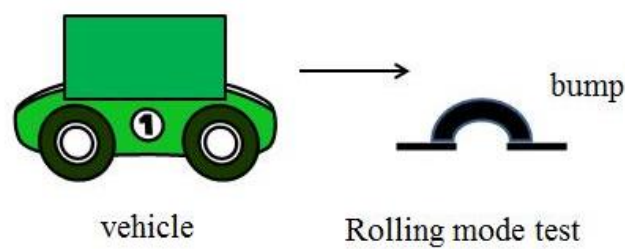

Figure 4. Rolling mode test

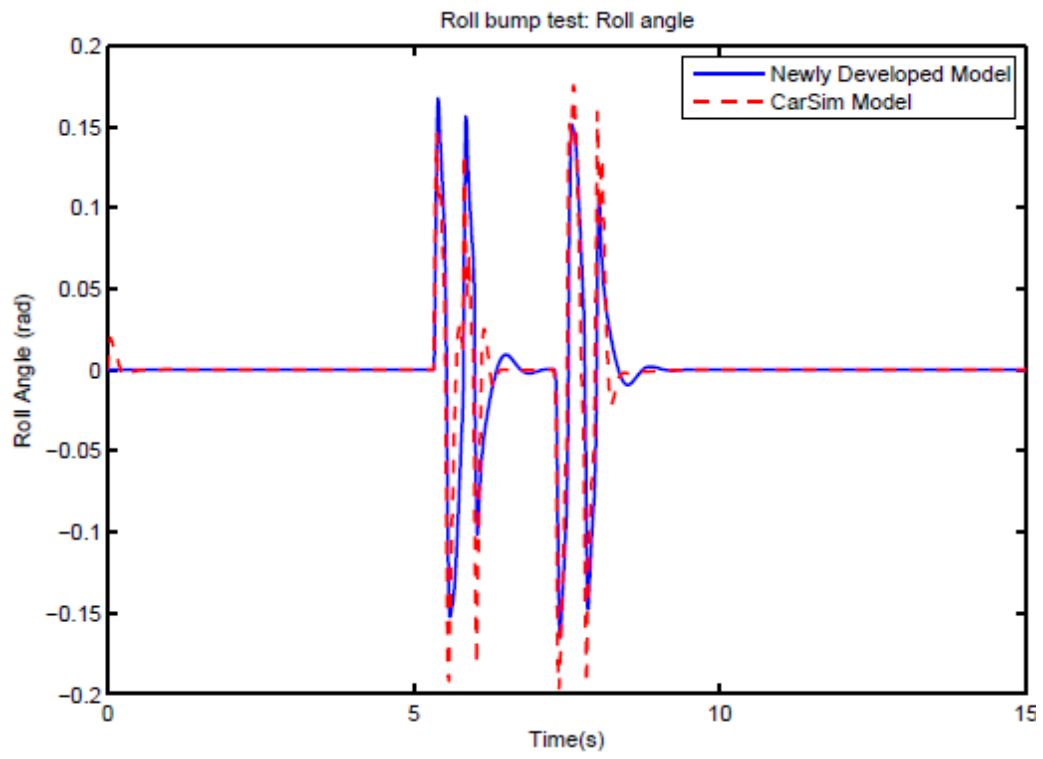

(a)

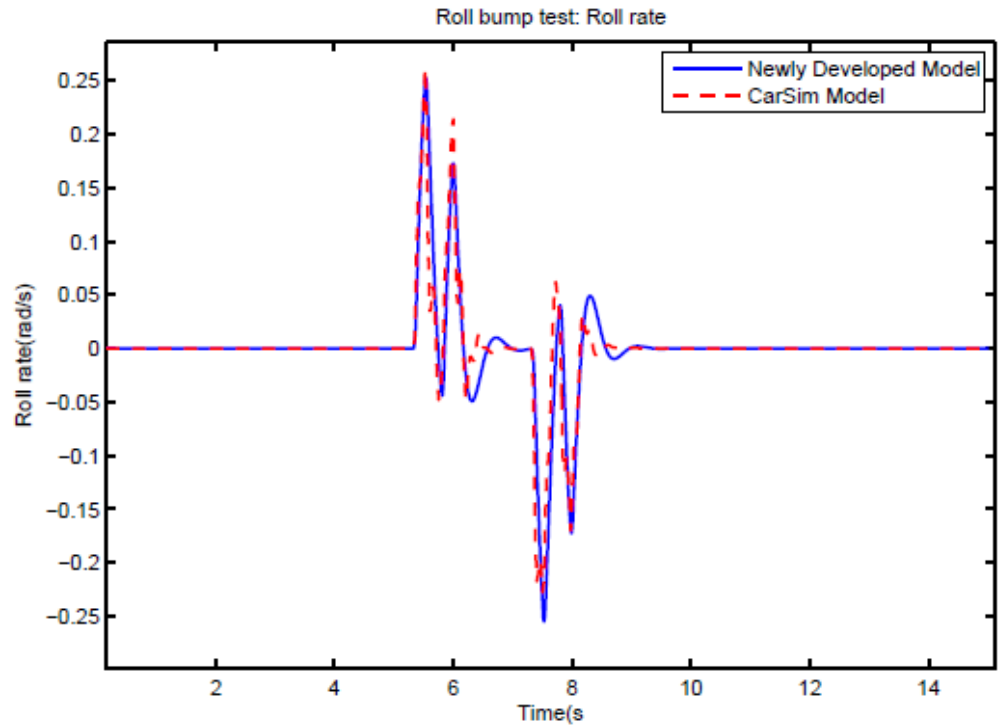

(b)

Figure 5. Roll bump test (a) roll angle response; (b) roll rate response 
The body roll angle of Figure 5 shows that the peak magnitudes from the full nonlinear vehicle model is almost identical with the CARSIM model response. The peak magnitudes at $t=5.396 \mathrm{~s}$ is about $0.1676 \mathrm{~m} / \mathrm{s}^{2}$ and $t=5.851 \mathrm{~s}$ is about $0.1564 \mathrm{~m} / \mathrm{s}^{2}$ when the front left tyre hit the bump and the peak magnitudes at about $7.585 \mathrm{~s}$ is about $0.1529 \mathrm{~m} / \mathrm{s}^{2}$ when the rear left tyre hit the bump. The roll rate graph that is generated from the simulation of full nonlinear vehicle model with CARSIM model results show a good correlation. The data from 0 to 5 second can be ignored as the vehicle is accelerating in order to achieve a constant speed $20 \mathrm{~km} / \mathrm{h}$ before hitting the bump.

\subsubsection{Handling Analysis Result}

Next, in the handling analysis, a double lane change manoeuvre test is used [23]. As for the double lane change test, it is taken from CARSIM where the steering wheel angle input for CARSIM model is exported to newly developed nonlinear vehicle model, thus both models were operated with the similar input condition. This manoeuvre test is operated in speed condition at $70 \mathrm{~km} / \mathrm{h}$. The full vehicle model performance with speed of $70 \mathrm{~km} / \mathrm{h}$ is shown in Figure 6 . The newly developed nonlinear vehicle model outputs trend are successfully replicated. However, there are some error in magnitude for roll angle and roll rate. This error in magnitude occurs because of nonlinearity properties of tyre model. The results indicated that the newly developed nonlinear vehicle model is behaving accurately with input manoeuvre.

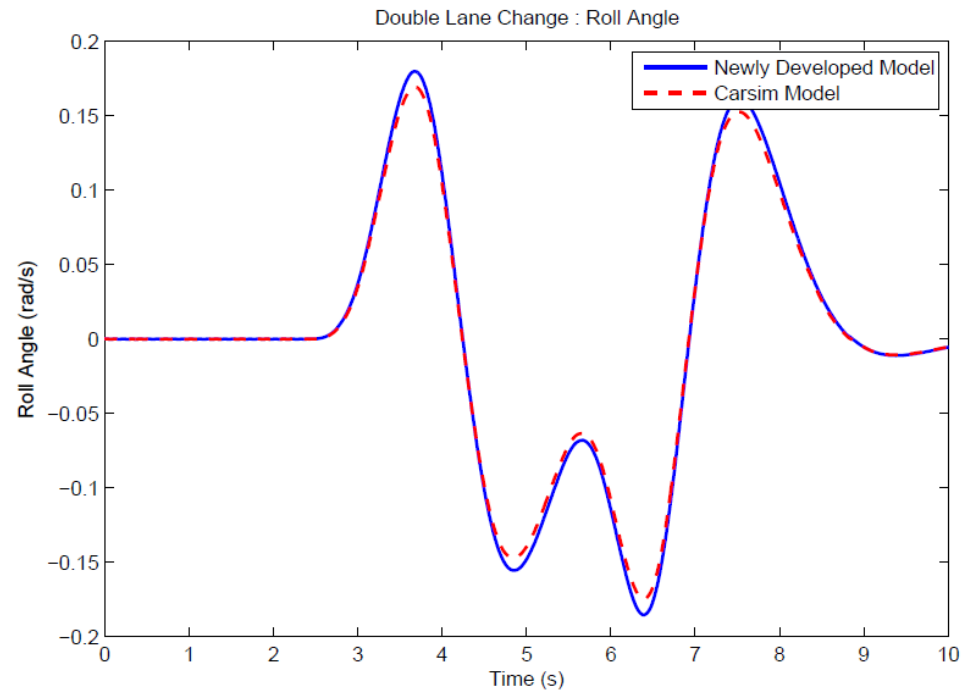

(a)

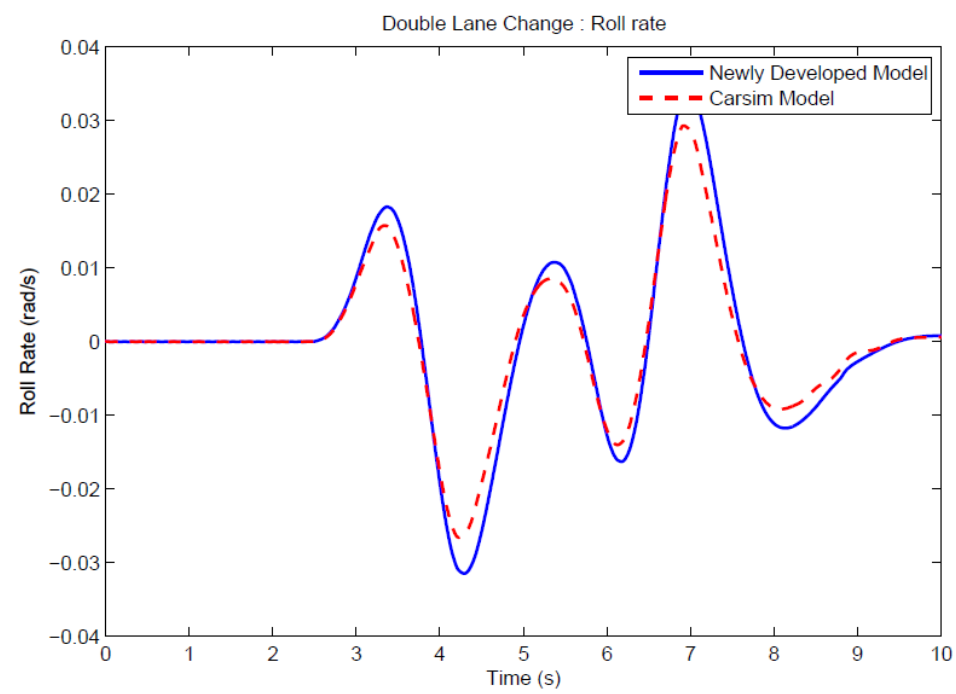

(b)

Figure 6. Double lane change (a) roll angle response; (b roll rate response 


\section{CONCLUSION}

A newly developed nonlinear vehicle model for an active anti-roll bar system using NSGA-II optimization method is successfully presented in this paper. This methodology is proposed to optimise the parameters of full nonlinear vehicle model based on ride and handling performances. The newly developed nonlinear vehicle model using NSGA-II optimization method has been verified with CARSIMEd version 4.51 that is a well-known vehicle dynamics software in order to determine its output response effectiveness. In the validation process, a comparison of the performance output trend of newly nonlinear vehicle model with CARSIM benchmark vehicle requires proper handling and ride test procedure. As such, two types of analysis procedures are used for the validation purpose which are roll mode bump and double lane change manoeuvre. The roll rate graph that is generated from the simulation of full nonlinear vehicle model with CARSIM model results show a good correlation in ride analysis part. However, there are some error in magnitude for roll angle and roll rate in handling analysis performance. This error in magnitude occurs because of nonlinearity properties of tyre model. For the conclusion, the results indicated that the newly developed nonlinear vehicle model is behaving accurately with input manoeuvre.

\section{ACKNOWLEDGEMENT}

The work presented in this study is funded by Universiti Kebangsaan Malaysia under GGPM Grant (vote no: GGPM-2017-087).

\section{REFERENCES}

[1] P. H. Cronj'e and P. S. Els, "Improving off-road vehicle handling using an active anti-roll bar," Journal of Terramechanics, vol. 47, no. 3, pp. 179-189, June 2010.

[2] H. Zamzuri, S. A. Saruchi, N. Zulkarnain, N. Wahid, M. H. M. Ariff et al., "Composite nonlinear feedback with disturbance observer for active front steering," Indonesian Journal of Electrical Engineering and Computer Science (IJEECS), vol. 7, no. 2, pp. 434-441, 2017.

[3] N. Zulkarnain, H. Zamzuri, Y. Sam, S. Mazlan, and S. Zainal, "Improving vehicle ride and handling using lqg cnf fusion control strategy for an active antiroll bar system," in Abstract and Applied Analysis, vol. 2014. Hindawi Publishing Corporation, 2014.

[4] S. A. Saruchi, H. Zamzuri, S. A. Mazlan, S. M. H. Fahami, and N. Zulkarnain, "Wheel synchronization control in steer-by-wire using composite nonlinear feedback," in Applied Mechanics and Materials, vol. 575. Trans Tech Publication, 2014, pp. 762-765.

[5] D. Cimba, J. Wagner, and A. Baviskar, "Investigation of active torsion bar actuator configurations to reduce vehicle body roll," Vehicle System Dynamics, vol. 44, no. 9, pp. 719-736, 2006.

[6] N. K. Cooperrider, T. M. Thomas, and S. A. Hammoud, "Testing and analysis of vehicle rollover behavior," SAE Technical Paper, Tech. Rep., 1990.

[7] M. Moza and S. Kumar, "Routing in networks using genetic algorithm," Bulletin of Electrical Engineering and Informatics, vol. 6, no. 1, pp. 88-98, 2017.

[8] S. Zamiri, S. Balochian, and H. Baloochian, "Multi objective optimization of multi component isothermal liquidphase kinetic sequence using multivariable pi control," Bulletin of Electrical Engineering and Informatics (BEEI), vol. 3, no. 4, pp. 277-284, 2014.

[9] S. Kalantari and M. SanieeAbadeh, "An effective multi-population based hybrid genetic algorithm for job shop scheduling problem," Bulletin of Electrical Engineering and Informatics (BEEI), vol. 2, no. 1, pp. 59-64, 2013.

[10] K. Deb, A. Pratap, S. Agarwal, and T. Meyarivan, "A fast and elitist multiobjective genetic algorithm: Nsga-ii," IEEE Transactions on Evolutionary Computation, vol. 6, no. 2, pp. 182-197, 2002.

[11] J. T. Pearson, R. M. Goodall, and I. Pratt, "Control system studies of an active anti-roll bar tilt system for railway vehicles," Proceedings of the Institution of Mechanical Engineers, Part F: Journal of Rail and Rapid Transit, vol. 212, no. 1, pp. 43-60, Jan. 1998.

[12] Q. Bai, "Trade-off analysis in multiobjective optimization for transportation asset management," Ph.D. dissertation, Purdue University, 2012

[13] T. Shi, S. Chen, D. Wang, and J. Chen, "Performance optimization of vehicle handling and stability using multiple surrogate models," Journal of Testing and Evaluation, vol. 44, no. 6, pp. 2100-2113, 2015.

[14] K. Caliskan, "Automated design analysis of anti-roll bars," Ph.D. dissertation, The Middle East Technical University, 2003.

[15] M. P. Bharane, M. K. Tanpure, and M. G. Kerkal, "Optimization of anti-roll bar using ansys parametric design language (apdl)," International Journal of Engineering Research and General Sciece, vol. 2, no. 5, 2014.

[16] K. Hudha, H. Jamaluddin, P. M. Samin, and R. A. Rahman, "Semi active roll control suspension (sarcs) system on a new modified half car model," SAE Technical Paper, Tech. Rep., 2003.

[17] H. Zamzuri, A. C. Zolotas, and R. M. Goodall, "Tilt control design for high-speed trains: a study on multiobjective tuning approaches," Vehicle System Dynamics, vol. 46, no. S1, pp. 535-547, 2008. 
[18] K. Deb, S. Agrawal, A. Pratap, and T. Meyarivan, "A fast elitist non-dominated sorting genetic algorithm for multi-objective optimization: Nsga-ii," in International Conference on Parallel Problem Solving From Nature. Springer, 2000, pp. 849-858.

[19] K. Deb, A. Pratap, S. Agarwal, and T. Meyarivan, "A fast and elitist multiobjective genetic algorithm: Nsga-ii," IEEE Transactions on Evolutionary Computation, vol. 6, no. 2, pp. 182-197, 2002.

[20] M. Sharifi, B. Shahriari, and A. Bagheri, "Optimization of sliding mode control for a vehicle suspension system via multi-objective genetic algorithm with uncertainty," Journal of Basic and Applied Scientific Research, vol. 2, no. 7, pp. 6724-6729, 2012.

[21] J. Herrero, X. Blasco, M. Mart'inez, C. Ramos, and J. Sanchis, "Non-linear robust identification of a greenhouse model using multi-objective evolutionary algorithms," Biosystems Engineering, vol. 98, no. 3, pp. 335-346, 2007.

[22] N. Zulkarnain, H. Zamzuri, S. A. Saruchi, A. Hussain, S. S. Mokri, A. Jedi, N. Razali, and I. N. A. Mohd Nordin, "Optimised combinatorial control strategy for active anti-roll bar system for ground vehicle," International Journal of Engineering \& Technology, vol. 7, no. 4.11, pp.140-144, 2018.

[23] N. Zulkarnain, N., F. Imaduddin, H. Zamzuri and S. A. Mazlan,"Application of an active anti-roll bar system for enhancing vehicle ride and handling," IEEE Colloquium on Humanities, Science and Engineering (CHUSER) (pp. 260-265). IEEE, 2012. 